\title{
Roles of mitophagy in cellular physiology and development
}

\author{
Jörn Dengjel ${ }^{1,2}$ • Hagai Abeliovich ${ }^{3,4}$
}

\begin{abstract}
The autophagic degradation of mitochondria, or mitophagy, has been shown to occur in eukaryotic cells under various physiological conditions. Broadly, these fall into two categories: quality-control related mitophagy and developmentally induced mitophagy. Quality-control related mitophagy, which is the lysosomal/vacuolar degradation of malfunctioning or superfluous mitochondria, is an important housekeeping function in respiring eukaryotic cells. It plays an essential role in physiological homeostasis and its deregulation has been linked to the progression of lateonset diseases. On the other hand, developmental processes such as reticulocyte maturation have also been shown to involve mitophagy. Importantly, there are clear differences between these processes. Unlike our knowledge of the more general degradation of soluble cytosolic content during starvation-induced macro autophagy, the mechanisms involved in the selective autophagic degradation of mitochondria have only recently begun to receive significant attention. Here, we review the current literature on these topics and proceed to provide specific examples from yeast and mammalian systems. Finally, we cover experimental
\end{abstract}

Hagai Abeliovich

ahagai@agri.huji.ac.il

1 Department of Dermatology, Medical Center, Freiburg Institute for Advanced Studies (FRIAS), ZBSA Center for Biological Systems Analysis, University of Freiburg, Habsburgerstr. 49, 79104 Freiburg, Germany

2 Department of Biology, University of Fribourg, Chemin du Musée 10, 1700 Fribourg, Switzerland

3 Department of Biochemistry and Food Science, Hebrew University of Jerusalem, Rehovot 76100, Israel

4 FRIAS Senior Fellow and Marie Curie Fellow of the European Union Freiburg Institute for Advanced Studies (FRIAS), University of Freiburg, Albertstr. 19, 79104 Freiburg, Germany approaches, with a focus on proteomic methods dedicated to the study of mitophagy in different systems.

Keywords Mitophagy · Autophagy $\cdot$ Physiology · Development $\cdot$ Membrane trafficking

\section{Mitochondria, genetic disease, and aging}

Mitochondria perform a variety of essential physiological functions in all eukaryotic cells. The production of ATP by oxidative phosphorylation is clearly the best recognized of these roles. However, no less essential are the roles played by mitochondria in fatty acid oxidation and the biosynthesis of isoprenoids, Heme, amino acids, iron-sulfur clusters and nucleotides, among others. Since the 1950s it has been recognized that oxidative metabolism harbors the potential for damage. In fact, it is estimated that anything between 0.1 to $4 \%$ of the total $\mathrm{O} 2$ consumption ends up as reactive oxygen species (ROS) under normal respiratory metabolism (Balaban et al. 2005). The localized production of ROS causes damage, which is manifested in mutagenesis of mitochondrial DNA, as well as protein and lipid oxidation reactions that have direct functional consequences. However, it can also indirectly lead to disruption of mitochondrial compartmentalization, further leading to leakage of cytochrome $\mathrm{c}$ and other cytotoxic factors. In addition, mitochondria with defective chemiosmotic coupling "short circuit" the ATP generating process, leading to an energy drain.

Gradual accumulation of mitochondrial DNA mutations has been invoked as an explanation for aging phenomena. In addition, many maternally-inherited forms of late onset diseases, such as type II diabetes, deafness, mitochondrial encephalomyopathy and optic neurophathy, to mention a few, have been linked to maternally-inherited mutations in the 
mitochondrial genome (Wallace 1999, 2005). In these heritable late-onset mtDNA diseases, mitochondria harboring deleterious mutations initially only occur as a fraction of the total mtDNA pool. With age, the mutant mtDNA pool expands through unknown mechanisms and begins to dominate cellular physiology, often in a tissue-specific manner (Wallace 1999, 2005). Within the framework of this theory, a role has been proposed for a quality control mechanism that identifies and deletes malfunctioning mitochondria, thus preventing clonal takeover of the system by the defective mitochondrial cohorts (Harman 1956; Wallace 1999, 2005; Ahlqvist et al. 2015).

A disease that is related to mitochondrial dysfunction but is not necessarily linked to inherited mitochondrial DNA mutations, is Parkinson's disease (PD). PD is a disorder in which neurons accumulate an amyloid form of $\alpha$-synuclein, a small, synaptic vesicle-associated protein (Wang and Hay 2015). This accumulation correlates with degeneration and death of dopaminergic neurons in the substantia nigra region of the brain, ultimately leading to major symptoms of the disease, such as resting tremor and rigidity of limbs. Agents that compromise mitochondrial function, such as rotenone and paraquat, induce a PD-like condition in rats (Greenamyre et al. 1999). Familial forms of PD are known to be caused by a set of mutations that map to specific genes, including those encoding the proteins $\alpha$-synuclein, LRRK2, DJ-1, ATP13A2, PINK1 and Parkin (Kumaran and Cookson 2015). As discussed below, two of these proteins, PINK1 and Parkin, are directly involved in mitochondrial quality control and in mitophagy.

\section{Mitophagy as a form of selective autophagy}

Autophagy is a general term referring to mechanisms that transport cytoplasmic material directly into the lumen of the lysosome or vacuole in eukaryotic cells. Three general types of autophagy are usually pointed out: macroautophagy, microautophagy and chaperone-mediated autophagy. Of these, macroautophagy is by far the best characterized. During macroautophagy, cellular membranes engulf cytoplasmic material to generate a double-membrane bound vesicle termed an autophagosome. Autophagosomes then fuse with vesicles derived from the endosomal system, thus forming amphisomes (Gordon and Seglen 1988; Sanchez-Wandelmer and Reggiori 2013) before finally fusing with lysosomes to generate autolysosomes in mammalian cells, or directly with the vacuole in yeast and plant cells. As a result of these fusion events the inner membrane of the autophagosome is exposed to lysosomal lipases that degrade it. This in turn exposes the cytosolic content sequestered within the inner membrane to additional lysosomal/vacuolar hydrolases leading to its degradation. Microautophagy is a conceptually similar mechanism in which the vacuolar/lysosomal membrane invaginates directly and pinches off an intraluminal vesicle that is then degraded by hydrolases. The main conceptual difference between microautophagy and macroautophagy is the absence of the intermediate, the autophagosome, in microautophagy. Chaperone-mediated autophagy is a completely different concept, in which individual unfolded protein molecules are thought to translocate across the lysosomal membrane through a channel created by the LAMP2A protein and driven by the ATP hydrolysis activity of cytosolic and lysosomal Hsc70 family members (Schneider and Cuervo 2014). A fourth mechanism that can be considered is multivesicular body (MVB) trafficking but this process is usually considered in the context of endocytosis and lysosomal targeting of secretory pathway components (Saksena et al. 2007; Scott et al. 2014).

Macroautophagy is known to be induced in all eukaryotic cells under nitrogen and amino acid starvation conditions. In some ways, this is considered a nonspecific process. For example, a mutant form of yeast vacuolar alkaline phosphatase, Pho8 $\Delta 60$, is mistargeted to the cytoplasm due to the absence of its N-terminal 60 amino acids. As such, it is a perfect innocent bystander in the sense that it is not a native cytosolic protein and does not carry out specific molecular interactions within the cytosolic milieu. Nonetheless, Pho8 $\Delta 60$ is-presumably unspecifically - carried to the vacuole by starvationinduced macroautophagy with an efficiency of around $10 \%$ over a 12-h starvation period (Noda et al. 1995). This, however, is not the complete story. Many cellular components require a selective receptor in order to be degraded through macroautophagy under starvation conditions (see below) and on the other hand other components appear to be completely spared.

Over the last 20 years, approximately 40 gene products have been identified as contributing to autophagy. Most of these have been discovered through genetic screens in yeast, thanks to the pioneering work of Yoshinori Ohsumi (Takeshige et al. 1992; Tsukada and Ohsumi 1993), Dan Klionsky (Klionsky et al. 1992; Harding et al. 1995) and Michael Thumm (Thumm et al. 1994). Several excellent and comprehensive recent reviews give a detailed account of our current knowledge and provide tables summarizing the core autophagy factors and their functions (Feng et al. 2014; Ktistakis and Tooze 2016). In what follows, we present a concise overview of these functions, focusing on their roles in mitochondrial autophagy. Overall, the vast majority of the factors composing the autophagic machinery fall into several major mechanistic classes that seem to be phylogenetically conserved. As original screens were performed in Saccharomyces cerevisiae, we stick to the respective yeast nomenclature:

1) The Atg12 ubiquitin-like modification system

Atg 12 is a 186 residue polypeptide that exhibits structural similarity to ubiquitin. Like ubiquitin it has a $\mathrm{C}$ terminal glycine, which can be conjugated to primary 
amine groups. Unlike ubiquitin it is only found to modify a second autophagy protein, Atg5, at lysine 149 (Mizushima et al. 1998), although in mammalian cells it was also reported to conjugate with Atg3, which is the E2 enzyme for Atg8 (Radoshevich et al. 2010; see below). Atg12 is conjugated via an enzymatic cascade very similar to that of ubiquitin. It is first activated by adenylation coupled to ATP hydrolysis, followed by formation of a thioester linkage to a cysteine residue on the E1-like enzyme Atg7. It is thence transferred to a cysteine residue on the E2-like enzyme Atg10, which mediates the conjugation reaction with Atg5. The Atg5-Atg12 conjugate has been observed to form large, membrane associated lattices in combination with the Atg16 protein (Kuma et al. 2002).

2) The Atg8 ubiquitin-like modification system

Atg8 is a small, 116 residue polypeptide that also displays a similar fold to ubiquitin (Paz et al. 2000; Sugawara et al. 2004; Koopmann et al. 2009; Noda et al. 2011). Unlike other UBLs, the C-terminal residue is an arginine. To uncover the reactive glycine, a redoxsensitive cysteine protease/amidase (Scherz-Shouval et al. 2007), Atg4, selectively removes the arginine residue, exposing glycine 115 as the C-terminal residue. Glycine 115 is then activated by $\operatorname{Atg} 7$ (which is a common E1-like enzyme for both UBL systems in autophagy) and transferred to a dedicated E2, Atg3. The activated Atg8 is then transferred, not to an amino group on a protein but on a lipid, phosphatidylethanolamine, in a reaction that is catalyzed by an E3-like activity that is assigned to the Atg12-Atg5-Atg16 lattice (Ichimura et al. 2000; Hanada et al. 2007). Atg8 has been shown to play a role in determining the size of autophagosomes, possibly by facilitating membrane fusion events at the growing sequestering membrane (Abeliovich et al. 2000; Nakatogawa et al. 2007; Xie et al. 2008). Atg8 is conjugated to both the outer autophagosomal membrane, facing the cytosol, and to PE in the inner membrane, facing the cytoplasmic cargo (Kirisako et al. 1999). These two populations of Atg8 have different fates: the Atg8 molecules on the outer membrane are hydrolytically released from PE in an Atg4-catalyzed reaction, while the Atg8 molecules in the inner membrane are degraded via autophagy. In addition to its role in autophagosome expansion, Atg8 also plays a role in the recruitment of specific cargo destined for autophagic trafficking or degradation (see below) and this may reflect a coupling mechanism between cargo availability and the expansion of the sequestering membrane. While yeast express only one species of Atg8-like protein, in mammalian cells there are at least 6 different members of this protein family. They include the MAP1LC3 sub-family, which includes LC3A, LC3B and LC3C and the GABARAP sub- family that includes GABARAP, GABARAPL1 and GABARAPL2/GATE16 (Shpilka et al. 2011). The relative roles of these proteins in autophagosome biogenesis is a topic of ongoing research (Behrends et al. 2010).

3) The Atg1 protein kinase complex

Amongst the core autophagy factors that were identified by genetic screening in yeast, Atg1 is the only protein kinase. It is an 890 amino acid residue protein with the kinase domain located in the N-terminal 350 residues. Atg1 seems to function within a complex containing proteins such as $A \operatorname{tg} 13, \operatorname{Atg} 17, \operatorname{Atg} 31, \operatorname{Atg} 29$ and $A \operatorname{tg} 11$. The precise makeup of the complex is thought to change as a function of the physiological state of the cell, viz-a-viz activation of macroautophagy. The phosphorylation state of Atg1 and its function seem to be regulated by the TOR signaling pathway, although roles for PKA and Sch9 have also been proposed (Budovskaya et al. 2004; Yorimitsu et al. 2007; Soulard et al. 2010; Egan et al. 2011).

The function of the kinase activity of Atg1 is somewhat controversial. Atg1 is known to autophosphorylate (Matsuura et al. 1997; Abeliovich et al. 2003) and an apparent phosphorylation activity of Atg1 has also been documented towards Atg2, Atg13, Atg6, Atg9, (Papinski and Kraft 2014; Papinski et al. 2014; Kamber et al. 2015) as well as additional proteins (Lin and Hurley 2016). Apart from autophosphorylation, the importance of these phosphosites for the induction of autophagy is not entirely clear. Using analog-sensitive kinase domain mutants, it was shown that the kinase activity is required for selective autophagy and not for starvation-induced autophagy (Abeliovich et al. 2003), although that result was later contested (Kabeya et al. 2005). More recently, it was shown using an orthogonal substrate-kinase pair that selective autophagy receptors and scaffold proteins activate Atg1 kinase activity and that rapamycin treatment overrides the need for these receptors in activating kinase activity (Kamber et al. 2015). It has not been verified whether the functional role of Atg1 kinase activity is as a selfregulating structural switch (Abeliovich et al. 2003) or a part of a signaling cascade that regulates downstream proteins such as Atg6 and Atg9 (Kamada et al. 2000; Kabeya et al. 2005; Papinski and Kraft 2014), or both. Atg1 is found in a complex with a second protein, Atg13 and it was shown that, upon starvation or inhibition of TOR kinase, the Atg1-Atg13 heterodimer associates with an Atg17-Atg29-Atg31 heterotrimer to form a dimer of pentamers (Köfinger et al. 2015) that can function to tether Atg9 vesicles (Suzuki et al. 2015; Rao et al. 2016) (see below). This interpretation would be consistent with a structural role for Atg1. In addition, in vitro phosphorylation of Atg13 by Atg1, which mimics the native phosphorylation pattern observed on Atg13 under nutrient replete conditions, inhibits the Atg9 vesicle tethering 
activity of the pentameric form (Rao et al. 2016). Atg1 can also directly bind to phosphoinositide-containing liposomes in a curvature-dependent fashion, although the biological significance of this activity is currently unclear (Ragusa et al. 2012; Rao et al. 2016).

In mammalian cells, two Atg1 orthologs have been identified: ULK1 and ULK2 (Unc-51 Like). These proteins are expressed ubiquitously in all mammalian tissues and interact with mammalian Atg13 (Chan et al. 2009; Hosokawa et al. 2009a) as well as with a putative Atg17like protein, RB1CC1/FIP200 (Hara et al. 2008; Alers et al. 2011). The mammalian ULK complexes lack Atg29 and Atg31 homologs but contain an additional protein, Atg101, which is missing from the yeast complex (Hosokawa et al. 2009b; Mercer et al. 2009). As in yeast, however, mammalian Atg13 is a phosphoprotein and its phosphorylation is under mTOR regulation. Knockdown of ULK1 but not ULK2, leads to an autophagy defect in HEK293 cells. However ulk1-/- knockout mice have a very limited phenotype that is much less severe than that of classical autophagy mutants such as atg5-/- or atg7-/knockouts. The ulk1-/- mice survive birth and do not display defects in classic starvation-induced autophagy but appear to be defective in mitochondrial clearance in erythrocyte maturation and display increased mitochondrial biomass in fibroblasts (Cheong et al. 2011). While ulk2-/- mice show no defects, the phenotype of the double ulk1-/- ulk2-/MEFs supports a redundant role of these two kinases in supporting autophagy (Cheong et al. 2011).

4) A type III phosphatidylinositol 3-kinase complex

Eukaryotic cells contain three distinct types of phosphatidylinositol 3-kinase (PI3K) activities with different biochemical attributes: types I, II and III. Each of these has additional sub classifications and variants as well, further complicating the picture. Type I PI3Ks play an indirect role in regulating autophagy in higher eukaryotes, by regulating mTOR activity in response to extracellular signals. However, type III PI3K is known to directly function in autophagic trafficking and this role is conserved in all eukaryotes. Type III PI3Ks are the only enzymes that phosphorylate PI to generate PI3P. PI3P is a lipid that is characteristic of the endolysosomal system and plays vital roles in vacuolar/lysosomal biogenesis as well as in endocytosis and related processes (Simonsen et al. 2001). In autophagy, type III PI3Ks are found as large protein complexes that are tethered to membranes. These complexes always include the catalytic subunit, Vps34, as well as a membrane-anchored (myristylated) protein kinase, Vps15/p150 and a third subunit, Vps30/Atg6/Beclin 1 (Stack et al. 1995). In addition to these invariant subunits, the holoenzyme also includes at least one additional component that seems to be function-specific. In yeast, there are two type III PI3K holoenzymes. In one complex, the additional subunit is Vps38. This complex plays a vital role in vacuole biogenesis and targeting processes, as well as in endocytosis. In the second complex, Vps38 is replaced by a different component called Atg14. This second complex (sometimes confusingly referred to as complex I) is essential for autophagic trafficking. In mammalian cells, there appear to be three type III PI3K complexes; two of them are analogous to the two yeast complexes. In one, a protein with analogous function to yeast Atg14, Atg14L/barkor, pairs with Beclin 1 (the mammalian Atg6/Vps30 homolog) to generate a complex that is essential for autophagy. In a second complex, Atg14L/ barkor is replaced with UVRAG, a protein with some resemblance to yeast Atg38 and this second complex is important for lysosomal trafficking/endocytosis. A third mammalian Vps34 complex contains UVRAG as well as Rubicon, a protein with no known yeast homolog. This third complex seems to negatively regulate both autophagy as well as lysosomal trafficking (Tabata et al. 2010). It was shown that PI3K activity is essential for generation of specialized PI3P patches on ER membranes (Axe et al. 2008), which then recruit PI3P binding proteins such as WIPI1 and deform into proto-autophagosomal structures known as omegasomes (Proikas-Cezanne et al. 2004; Polson et al. 2010).

5) Atg9 and ancillary proteins

Surprisingly, only one of the core autophagic factors that are absolutely required for all forms of macro autophagy is an integral membrane protein. Yeast Atg9 is a large 997 AA residue protein with 6 predicted transmembrane domains. In yeast cells, Atg9 localizes to small cytoplasmic vesicles. Upon induction of autophagy by nitrogen starvation or TOR inhibition, additional vesicles are formed de novo by budding from the trans-Golgi network and each round of autophagosome biogenesis requires the coalescence of approximately three such Atg9 vesicles. De novo formation of these Atg9 vesicles requires Atg23 and Atg27 (Mari et al. 2010; Yamamoto et al. 2012). These Atg9-containing vesicles are then tethered in a step dependent on the Atg1 pentameric complex (see above) to nucleate autophagosomes.

Once an autophagosome forms, Atg9 is located on the outer membrane of the autophagosome and is recycled to the Golgi. The location within cells at which recycling occurs is controversial, with some reports indicating direct recycling from the autophagosome while others indicate recycling of Atg9 from the vacuole after autophagosome-vacuole fusion (Mari et al. 2010; Yamamoto et al. 2012).

In mammals, mATG9 is also essential for autophagy, as the respective knockout mice do not survive the neonatal starvation period, similar to ATG5-/- mice and the atg9-/- MEFs show a defect in autophagy (Saitoh et al. 
2009). Under basal conditions, mammalian Atg9 shows a bimodal distribution, localizing to both the trans-Golgi network (TGN) and late endosomes (Young et al. 2006; Orsi et al. 2012). Upon the induction of autophagy by nutrient deprivation or mTOR inhibition, the distribution of mAtg9 shifts and under these conditions the protein is found mostly colocalized with peripheral endosomes. This redistribution of mAtg9 localization appears to depend on ULK1, mVps34 and WIPI (Young et al. 2006; Orsi et al. 2012). The model that has been proposed to explain these results is that mAtg9 shuttles between endosomes and the TGN and that induction of autophagy correlates with an inhibition of the endosome-to-TGN route, leading to accumulation of the protein on endosomes. One model for Atg9 function, in both yeast as well as mammalian cells, is that it plays a role in the delivery of lipid and membranes to feed the expansion of the sequestering membrane, although formal proof of this concept has been elusive thus far.

6) Selective autophagy receptors

In recent years, it has been acknowledged that many selective forms of autophagy exist and some of these can be uncoupled from starvation conditions. The classical form of selective autophagy is the yeast CVT pathway. In the CVT pathway, a cytosolic precursor of the vacuolar protease aminopeptidase I (Ape1) is engulfed by autophagic membranes and delivered to the vacuole in a process that depends on many of the same factors as starvation-induced macroautophagy. The Cvt pathway, however, occurs in normally growing yeast cells and does not require nitrogen starvation for its induction. Rather, it requires a receptor (or rather adaptor) protein called Atg19 (Shintani et al. 2002). Atg19 binds to dodecameric Ape1 precursor complexes on the one hand and to Atg8 and Atg11 on the other hand. By linking the cargo, Ape1 with the autophagic machinery Atg19 allows selective delivery of Ape1 to the vacuolar lumen. A second protein $\alpha$-mannosidase (Ams1) is also known to be delivered to the vacuole using the Cvt pathway. Consistent with our notions of nonselective macroautophagy, knockout of ATG19 abrogates Cvt trafficking of Ape1 but still allows an inefficient transport of precursor Ape1 to the vacuole upon nitrogen starvation, with an efficiency roughly similar to that of Pho8 $\Delta 60$ (Shintani et al. 2002).

The Cvt pathway is a very instructive paradigm for selective autophagy as it embodies the defining characteristics of such processes: all forms of selective autophagy employ adaptors and receptors, which link the designated cargo with the autophagic machinery and usually with
Atg8 or an Atg8-like protein.

There has been a veritable explosion of selective autophagy processes described recently. A partial list includes aggrephagy (Øverbye et al. 2007; Wong et al. 2012) (autophagy of aggregated proteins), ribophagy (Kraft and Peter 2008), ER-phagy (Khaminets et al. 2015; Mochida et al. 2015), nucleophagy (Mijaljica and Devenish 2013; Mochida et al. 2015), lipophagy (Singh et al. 2009), ferritinophagy (Mancias et al. 2014), lysophagy (Hung et al. 2013) (lysosome autophagy), xenophagy (degradation of intracellular pathogens) (Singh et al. 2006; Chauhan et al. 2015), to name a few (for a full review, see Stolz et al. 2014). By definition, each such process designates a receptor or adaptor protein that links the selective autophagic cargo to an Atg8-like protein. The selective autophagy receptors interacting with Atg8-like proteins through dedicated, evolutionarily conserved motifs termed LIR (LC3 interacting region, $\mathrm{W} / \mathrm{F} / \mathrm{YxxL} / \mathrm{I} / \mathrm{V}$ ) or AIM (Atg8 interaction motif) motifs selective macroautophagy, are no exception: As described below in more detail, all forms of mitophagy involve such receptor and adaptor proteins. However, the identity of the receptor/adaptor and its regulation seem to vary between organisms, as well as between different forms of mitophagy in the same organism.

\section{Mitophagy as a quality control mechanism in mammalian cells}

Mitochondria exhibit a wide spectrum of quality control mechanisms, which include proteasome-mediated degradation of outer-membrane proteins (OMMAD) as well as endogenous proteases. However autophagy is the only known cellular mechanism that can actually mediate the degradation of entire organelles. Selective mitochondrial autophagy was first described by the Lemasters laboratory (who also coined the term "mitophagy"; RodriguezEnriquez et al. 2004, 2006, 2009). Later, it was confirmed that, in specific types of mammalian cells, depolarized mitochondria are selectively degraded by mitophagy (Narendra et al. 2008; Twig et al. 2008). The overall scheme suggested by these studies implies that (1) depolarized mitochondria are unable to undergo further fusion events; (2) $85 \%$ of fission events lead to formation of one depolarized and one hyperpolarized compartment, suggesting an active process segregating intra-mito chondrial material; (3) the post-fission state is the "resting state" in the mitochondrial life-cycle and fusion is rapidly followed by fission; and finally (4) depolarized mitochondria, formed by selective fission, are selectively auto phagocytosed. 
Recently, the molecular mechanisms underlying mitochondrial engulfment in mammalian cells have been characterized. However, some details are still under debate. The mitochondrial membrane-anchored protein kinase PINK1 is normally imported into mitochondria. In energized mitochondria, it is processed by presenilin associated rhomboid-like protease (PARL) followed by its degradation, which is suggested to happen either inside mitochondria, or in an ubiquitin- and proteasome-dependent manner following retrotranslocation to the cytosol (Jin et al. 2010; Meissner et al. 2011; Yamano and Youle 2013). In depolarized mitochondria, PINK1 is stabilized on the mitochondrial outer membrane (Narendra et al. 2008; Jin et al. 2010; Matsuda et al. 2010; Narendra et al. 2010) and phosphorylates ubiquitin (Ub) (ShibaFukushima et al. 2012; Kane et al. 2014; Kazlauskaite et al. 2014; Koyano et al. 2014) in addition to phosphorylating Parkin, which is a ubiquitin-conjugating E3 enzyme (Narendra et al. 2008; Jin et al. 2010; Matsuda et al. 2010; Narendra et al. 2010); (Kondapalli et al. 2012; Shiba-Fukushima et al. 2012; Koyano et al. 2014). The combination of phospho-Parkin and phospho-Ub functions as a feed-forward loop amplifying the mitophagic signal (Ordureau et al. 2014). Two phosphoubiquitin-specific autophagy receptors, optineurin and NDP52, have been shown to be recruited to PINK1presenting mitochondria using mass spectrometry-based proteomics (Heo et al. 2015; Lazarou et al. 2015). Interestingly, both of these proteins have been previously implicated in xenophagy (Thurston et al. 2009; Wild et al. 2011). Optineurin binding leads to TBK1 recruitment, which in turn phosphorylates optineurin, thus further enhancing its ubiquitin binding capacity (Heo et al. 2015; Richter et al. 2016). In addition, TBK1 has been shown to phosphorylate additional autophagy receptors, such as NDP52, TAX1BP1 and SQSTM1 (Heo et al. 2015; Richter et al. 2016). Additional, alternative Parkin receptors have also been suggested in the past: mitofusin 2 was suggested to be phosphorylated by Pink1, with phosphomitofusin 2 functioning as a Parkin receptor (Chen and Dorn 2013). For a general summary of this sequence of molecular events, see Fig. 1b. As Parkin is activated by phosphoubiquitin, it ubiquitinates numerous mitochondrial proteins and among them are mitofusin 1 and 2 (Narendra et al. 2010; Tanaka et al. 2010). This explains the inability of depolarized mitochondria to fuse with polarized mitochondria. While these results provide a mechanistic explanation for much of the data, several important questions remain. For example, given that $85 \%$ of fission events lead to segregation between depolarized and hyperpolarized mitochondria (Twig et al. 2008), one must hypothesize the existence of some active segregation mechanism between functional and defective
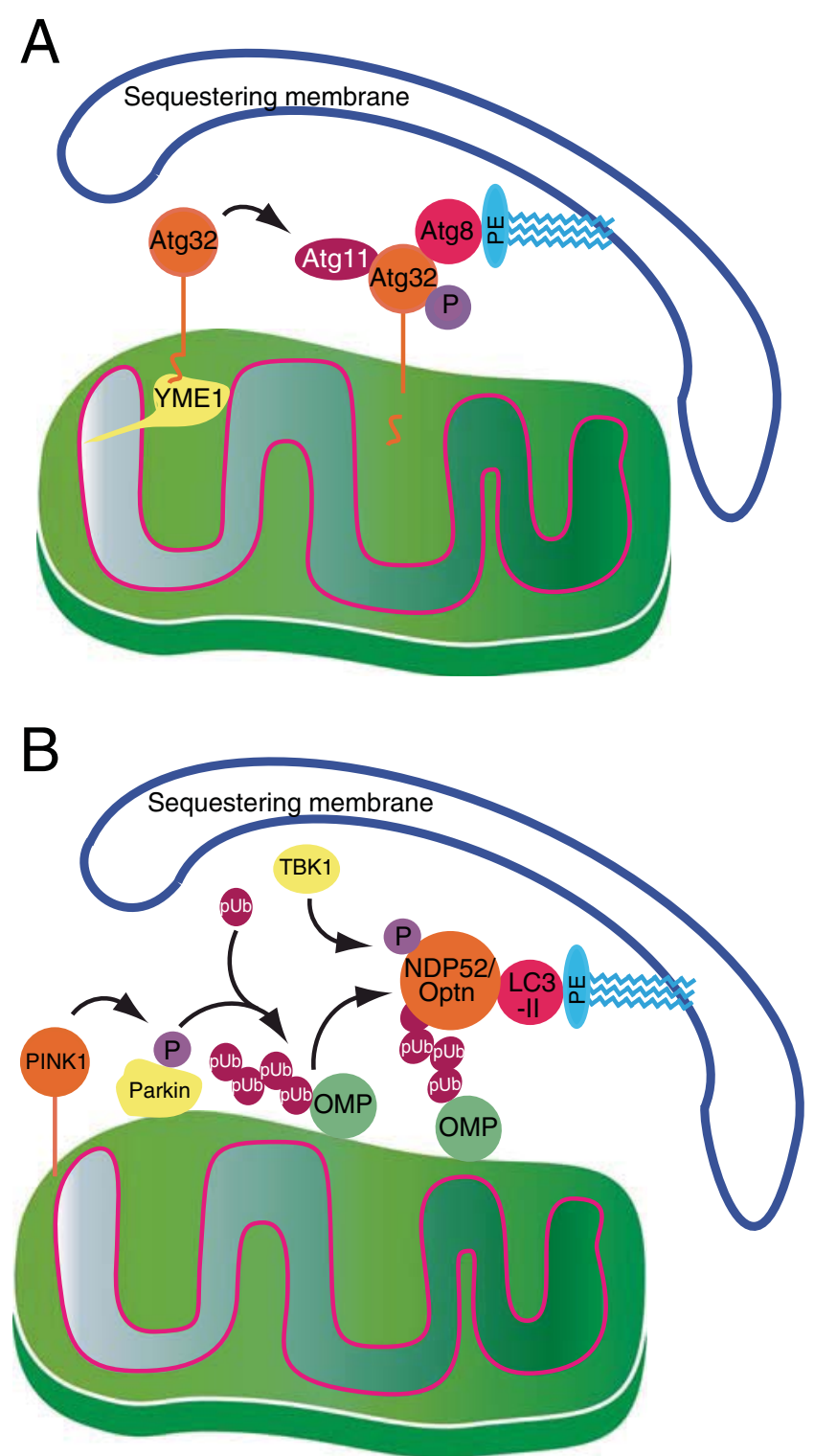

Fig. 1 Comparison of sequestering membrane recruitment to mitochondria in a yeast and $\mathbf{b}$ mammalian cells. In yeast (a), activation of Atg32 requires a proteolytic clipping step, mediated by the AAA protease Yme1, as well as phosphorylation. Activated Atg32 is then able to interact with lipidated Atg8 as well as with the Atg11 scaffold protein. b In mammalian cells, loss of mitochondrial membrane potential stalls PINK1 import and stabilizes it on the outer membrane, by preventing constitutive PARL-dependent proteolysis of imported PINK1 (not depicted). The stabilized PINK1 phosphorylates both Parkin, as well as ubiquitin. This simultaneously recruits Parkin to mitochondria and activates it to phospho-ubiquitylate mitochondrial outer membrane proteins, which in turn are recognized by the redundant mitophagy receptors NBP52 and Optineurin, thus linking LC3-II (the mammalian ortholog of lipidated Atg8) with outer mitochondrial proteins. Finally, Optrineurin activation is regulated by TBK1 through phosphorylation on serine 177

mitochondrial components that somehow senses the Pink1 load of the outer mitochondrial membrane. The nature of such a mechanism is currently ground for speculation and is an area of active research. 


\section{Mitophagy during development in multicellular organisms}

Erythrocyte maturation in mammals involves the complete removal of organelles, including mitochondria. It was shown that mitophagy contributes to the degradation of mitochondria in differentiating reticulocytes. Thus, knocking out canonical autophagy proteins such as Atg5 abolishes some but not all mitochondrial degradation during erythrocyte maturation. It was shown that a specific mitochondrial outer membrane protein, NIX (also known as BNIP3L) functions as a receptor that interacts with the autophagic machinery to mediate this process (Sandoval et al. 2008; Novak et al. 2010). Thus, in NIX knockout animals, a significant proportion of red blood cells $(30-50 \%)$ show persistence of mitochondria in differentiated erythrocytes but no persistence of other organelles such as peroxisomes, secretory pathway members, or ribosomes. Consistent with the assignment of NIX as a mitophagy receptor, it contains a LIR domain and mutations within this domain impair its function (Novak et al. 2010).

In addition to the direct role of mitophagy in erythrocyte maturation, mitophagy has been implicated in developmental transitions in muscle tissue. It was recently shown that, upon differentiation of mouse myoblasts, mitophagy is induced and is necessary for differentiation (Sin et al. 2016). Furthermore, essential metabolic transitions that occur during differentiation of cardiomyocytes have been shown to be mitophagydependent (Gong et al. 2015).

Mitophagy in mammalian cells is not limited to development and mitochondrial depolarization. An additional experimental framework in which mitophagy has been observed is during hypoxic treatment of mammalian cells in culture. Hypoxia-induced mitophagy appears to be a protective response (Zhang et al. 2008; Bellot et al. 2009). Later, it was discovered that FUNDC1, a mitochondrial outer membrane protein, binds LC3 and functions as a mitophagy receptor under these conditions (Liu et al. 2012).

\section{Mitophagy in the yeast $S$. cerevisiae}

In S. cerevisiae, the presence of mitochondria in nitrogenstarvation induced autophagic bodies was demonstrated by EM (Takeshige et al. 1992), similar to what was shown for mammalian cells three decades earlier (Deter et al. 1967). However, those pictures appear to be anecdotal, as only a few mitochondria are actually engulfed by autophagosomes during nitrogen starvation in S. cerevisiae. Standard nitrogen starvation protocols, which are used to assay starvationinduced macroautophagy in yeast (transfer from glucosebased minimal medium to glucose-based minimal medium lacking nitrogen; inhibition of TORC1 in minimal and rich glucose-based medium), do not yield any discernible biochemical or structural manifestations of mitophagy.

The first reports on mitophagy in yeast utilized stress conditions that were induced by mutation. Priault et al. (2005) utilized fmcl $\Delta$ mutants. These cells fail to properly assemble the $\mathrm{F}_{1} \mathrm{~F}_{0}$ ATPase at high temperatures. Their study showed that under anaerobic conditions and after $24 \mathrm{~h}$ at nonpermissive temperature, fmcl $\Delta$ cells appear to accumulate autophagosomes. Concomitantly, levels of ATPase subunits specifically decline, as well as the levels of mitochondrial porins. The authors suggested that these data point to selective autophagy being induced as a result of depolarization but did not demonstrate, either morphologically nor biochemically, that mitochondrial material was actually being degraded in the vacuole under these conditions.

Nowikowsky et al. later showed that upon depletion of $\mathrm{K}+$ / $\mathrm{H}+$ antiporter activity, mitophagy occurs as an early event (Nowikovsky et al. 2007). They reported that the degradation of mitochondria under these conditions occurs via a microautophagic mechanism, in which vacuoles directly engulf mitochondria, thus generating mitochondria-containing autophagic bodies without forming cytosolic autopha gosomes. They also demonstrated that Dnm1, a dynaminlike protein that is required for mitochondrial fission, is required for this type of mitophagy. In both of these early studies, the introduction of a genetic lesion causes a physiological defect in mitochondrial function that leads to mitochondrial degradation in the vacuole, via mitophagy.

Initial reports of mitophagy occuring en masse in wild-type S. cerevisiae (Kissova et al. 2004) showed that yeast cells grown in rich lactate medium and then transferred to minimal nitrogen starvation on glucose, display mitophagy within $12 \mathrm{~h}$ (as measured by transfer of a mitochondrially targeted GFP to the vacuolar lumen). However, as the procedure involves a direct response to starvation coupled with a change in carbon source, it is unlikely to reflect a physiological quality control event.

The observation of mitophagy in S. cerevisiae without additional experimental manipulation was first described by Tal et al. (2007) in wild-type yeast cells incubated into stationary phase (beyond 3 days of culture) under respiratory conditions ( $\mathrm{Tal}$ et al. 2007). This phenomenon may indeed represent a quality control process, as suggested by several observations: (1) standard nitrogen-starvation protocols do not lead to mitophagy; (2) macroautophagy occurs already on day 1 of a 3-day stationary phase mitophagy protocol (Journo et al. 2009) and thus mitophagy is temporally distinct from starvation-induced macroautophagy; and (3) the genetic requirements for starvation-induced mitophagy (coupled to a simultaneous change in carbon source and nitrogen availability) and stationary phase mitophagy do not fully overlap (Kanki et al. 2010). 
This stationary phase mitophagy protocol was adapted to carry out large-scale screenings of the yeast knockout collection identifying strains that lost the ability to transfer mitochondrial GFP to the vacuole under respective conditions. These screens identified several interesting genes (Kanki et al. 2009; Okamoto et al. 2009; Kanki et al. 2010). The general message of these studies indicates that mitophagy is a type of selective autophagy. As in all other instances of selective autophagy, mitophagy requires most of the common autophagy machinery (for review, see Feng et al. 2014) and additionally a specific mitophagy receptor. This receptor was identified as Atg32, a type II integral membrane protein of the outer mitochondrial membrane (see Fig. 1a) (Kanki et al. 2009, 2010; Okamoto et al. 2009). Atg32 functions as a mitophagy receptor by interacting with components of the autophagy machinery, e.g., Atg11, which are specific to selective autophagic pathways such as the Cvt pathway and pexophagy, the selective degradation of peroxisomes. Atg32 seems to be expressed uniformly on yeast mitochondria. However, its overall levels increase under mitophagyinducing conditions in a redox-dependent fashion (Okamoto et al. 2009). Moreover, overexpression of Atg32 leads to an increase in the amplitude of the mitophagic response. More recent work demonstrated that Atg32 undergoes posttranslational modifications that may regulate its activity. It is phosphorylated on serine 114 in its N-terminal cytosolic domain (Aoki et al. 2011) and it is proteolytically cleaved within its intermembrane space C-terminal domain by the mitochondrial AAA protease Yme1 (Wang et al. 2013). The levels of Atg32 respond to the availability of glutathione (Okamoto et al. 2009) and glutathione levels can be manipulated by defects in phospholipid metabolism (Sakakibara et al. 2015), although it is unclear to what degree changes in phospholipid metabolism accompany the onset of mitophagy in wild-type cells. While no direct orthologue of Atg32 is known in mammalian cells, it is clearly functionally analogous to mammalian mitophagy receptors such as optineurin and NDP52 (see Fig. 1).

\section{The interrelationship between redox stress and mitophagy}

Within the mitochondrial theory of aging, mitophagy is hypothesized to play a vital role in alleviating the accumulation of defective mitochondrial components. Nonfunctional mitochondria should either hamper cells by generating harmful substances such as reactive oxygen species (ROS), or by being a metabolic burden. Paradoxically, no increase in the levels of ROS under conditions where mitophagy was blocked was found (Kanki et al. 2009). However, Twig et al. (2008) described an increase in oxidized proteins in COS7 cells expressing FIS1 RNAi or a dominant negative DRP1 mutant leading to impaired mitophagy. This result has been corroborated in yeast by Journo et al. (2009), who found that aup $1 \Delta$ cells, which exhibit decreased mitophagy (Tal et al. 2007), accumulate more oxidized proteins than wild-type cells under conditions of stationary phase mitophagy. Interestingly, Deffieu et al. (2009) showed that the antioxidant N-acetyl-Lcysteine (NAC) can inhibit mitophagy in yeast but not general nitrogen starvation-induced macroautophagy. The effect on mitophagy was due to an increase in glutathione levels and not due to changes in ROS levels. In agreement, glutathione synthetase mutants show a significantly higher level of mitophagy that is not inhibited by NAC. These results suggest that accumulation of oxidized molecules, i.e., proteins, may trigger mitophagy. However, it should also be mentioned that NAC was shown to inhibit ATG32 expression (Okamoto et al. 2009).

\section{Targeting, segregation and engulfment of mitochondria}

Mitophagy in S. cerevisiae does not lead to the degradation of all mitochondria. This by itself is not surprising, as mitochondria are essential for cell survival. In addition, however, the data of Twig et al. (2008) as well as Narendra et al. (2010) suggest that depolarized mitochondria are generated specifically during fission events and that these depolarized units are specifically targeted for mitophagy. Again, a non-random segregation process is supported by the fact that $85 \%$ of mitochondrial fission events were shown to result in one significantly depolarized and one significantly hyperpolarized daughter mitochondrion. Such segregation, coupled with fission, may ultimately 'distill' defective mitochondria out of the dynamic network. Combined with the observation that depolarization of mitochondria leads to ubiquitination of mitofusins (Ziviani and Whitworth, 2010; Ziviani et al. 2010), one may hypothesize that depolarized mitochondria are marked as defective by a specific molecular signature. In mammalian cells, this signal appears to be phospho-ubiquitin (Fig. 1). A respective signal in yeast cells is still missing. However, it is likely to involve post-translational modifications of Atg32, as discussed above.

Several observations suggest that degraded mitochondrial components are not a random representation of mitochondrial biomass and that these components are sorted prior mitophagy. The observation that asymmetric fission results in one hyperpolarized and one depolarized mitochondrion (Twig et al. 2008), together with the fact that mitochondrial dynamics and content mixing and not mitochondrial size, determine the rate of mitophagy suggest a distillation-type mechanism for separating intra-mitochondrial components (Abeliovich 2011; Abeliovich et al. 2013). Interestingly, a direct interaction between Atg11, an autophagy factor functioning in cargo selectivity and Dnm1, a dynamin like ATPase 
required for mitochondrial fission has been reported (Mao et al. 2013). Also, mitochondrial fission is known to occur at ER-mitochondrial contact sites (Friedman et al. 2011), which were shown to be important for the induction of mitophagy in yeast (Böckler and Westermann 2014).

\section{Mitophagy as a potential quality control agent in mitigating mtDNA heteroplasmy}

As mentioned above, many late-onset mtDNA-linked disorders occur due to the age-dependent clonal takeover of the mtDNA cohort by mutations that are either maternally inherited as heteroplasmic oocyte mtDNA or by somatic mutations that arise due to the error-prone nature of mtDNA replication (Wallace 2005, 2010). The mechanism of clonal takeover is still being debated (Wallace and Chalkia 2013). One popular hypothesis posits that mitophagy can identify mitochondrial fragments that contain such mutant DNA molecules and "purify" the network (Busch et al. 2014). This is consistent with the 'late-onset' etiology of these diseases, since autophagy and mitophagy are known to decrease with age in metazoans (Vittorini et al. 1999; Cuervo 2008; Lipinski et al. 2010; Cui et al. 2012). The manner in which recognition of mutant mtDNA could occur is an active area of research. Open reading frames encoded by mtDNA encode, as a rule, polytopic integral membrane proteins of the inner mitochondrial membrane, which function in the electron transport chain. One recent discovery has been that, in contrast with mitochondrial matrix protein, these proteins intermix much more slowly within the mitochondrial network (Wilkens et al. 2013; Busch et al. 2014). In addition, the rate of diffusion of these membrane proteins is similar to that of mitochondrial nucleoids. Thus, it is envisaged that the nucleoids form relatively static "domains" that are enriched in the products of that specific nucleoid. Thus, a mutation in a mitochondrial ORF would generate a defective mitochondrial domain that could be isolated via repeated fission and fusion to generate a defective, 'edible' mitochondrion. However, some facts are difficult to reconcile with this hypothesis. For example, some pathological mtDNA mutations, such as the MELAS mutation (Goto et al. 1990) are located in non-protein coding regions such as tRNA molecules, which should be freely diffusible in the matrix. Since tRNA molecules are not hypothesized to be diffusion-constricted, they would not provide the linkage between phenotype and genotype that is essential for purification. Despite this, segregation effects of the MELAS mutation have been reported (Hämäläinen et al. 2013). During iPSC differentiation of MELAS patient-derived iPSCs to neuronal lineages, it was observed that expression of the defective mitochondrial tRNA led to selective degradation of mitochondrial electron transport complex I via mitophagy. This process appears to involve intra-mitochondrial protein segregation
(Hämäläinen et al. 2013; Pickrell and Youle 2013). Additionally, it appears that the mutant DNA also undergoes a segregation effect, as differentiation involved a shift to homoplasmy but did not involve any reduction in mtDNA copy number (Hämäläinen et al. 2013).

However, efforts to demonstrate mutant mtDNA purification by mitophagy in whole animals have met with little success. Pickrell and Youle (2013) and Pickrell et al. (2015) found that when Parkin KO mice were crossed with mice carrying mutant mitochondrial DNA polymerase, a lesion that leads to accumulation of mutant mitochondria and early aging phenotypes, the mice displayed L-DOPA reversible motor defects, without effects on non-dopaminergic neurons. Importantly, the double mutant mice did not show any effects that would imply a Parkin-dependent 'purification' of mutant mtDNA (Pickrell et al. 2015). In contrast, previous results from work in cell lines showed precisely such a purifying effect of Parkin expression on heteroplasmy (Suen et al. 2010). The lack of a Parkin-dependent purification activity in whole mice may simply reflect the fact that Parkindependent mitophagy is not the only form of mitophagy. In agreement with this latter interpretation, Diot et al. (2015) described conditions under which heteroplasmic mtDNA populations in patient-derived primary fibroblasts underwent purification in a mitophagy-dependent manner. Since they could not detect Parkin expression in their cells, they suggested that this purification process is Parkin-independent. In summary, it is possible that mitophagy responds to protein damage and that it attenuates the penetrance of mtDNA mutants in heteroplasmy, without addressing the core genetic defect. However, it should be borne in mind that some studies in cell lines have suggested a role for mitophagy in directly decreasing mutant mtDNA load. Thus, much work still remains do be done in order to clarify whether mitophagy plays an agedependent role in preventing clonal takeover by mutant mtDNA in heteroplasmies.

\section{Analyses of mitochondrial function and turnover by mass spectrometry-based proteomics approaches}

As mentioned above, mass spectrometry-based proteomics has been successfully used to study the regulation of proteins involved in mitophagy, highlighting the power of these approaches (Heo et al. 2015; Richter et al. 2016). Indeed, mass spectrometry-based proteomics has played a vital role in characterizing mitochondrial biology. As mitochondrial proteins are encoded by nuclear and mitochondrial genes, gene expression analyses cannot answer the question which proteins localize to mitochondria and what their function might be. Thus, already more than a decade ago, scientists aimed at generating a comprehensive compendium of mitochondrial proteins. Initially, qualitative experiments were performed: purified 
mitochondria were analyzed by shot-gun proteomics approaches to generate a comprehensive organellar inventory (Mootha et al. 2003; Sickmann et al. 2003) and to map posttranslational modifications such as phosphorylation of organellar proteins (Reinders et al. 2007). An inherent problem in these early studies was the presence of co-purifying contaminants that could be misidentified as genuine mitochondrial proteins. This is a common problem in biochemical fractionation/purification experiments, as one cannot enrich organelles to purity.

More recently, quantitative proteomic approaches were developed, which minimize these problems. Label-free approaches that incorporate gradient fractionation profiles (Foster et al. 2006) and approaches that monitor degrees of enrichment (Pagliarini et al. 2008), both allow a better discrimination between truly organellar and contaminating proteins. Indeed, this led to the identification of novel mitochondrial proteins as well as the identification of genes mutated in mitochondrial diseases (PMID; Pagliarini et al. 2008). With the introduction of relative quantification approaches such as stable isotope labeling by amino acids in cell culture (SILAC) (Ong et al. 2002), more sophisticated experiments could be designed. Amongst others, mitochondrial sub-compartments, like the inter-membrane space proteome (Vögtle et al. 2012), mitochondrial protein interactomes (Petrungaro et al. 2015) and mitochondrial protein import (Wrobel et al. 2015) have been characterized in detail.

One of the newest methodological developments to study mitochondrial function by mass spectrometry is termed proximity proteomics (Rees et al. 2015). Different approaches have been designed that all rely on the covalent modification of proteins in close proximity of proteins-of-interest, e.g., by biotin, which allows subsequent biochemical enrichment and determination of "protein neighborhoods". An engineered ascorbate peroxidase (APEX) was initially used to biotinylate mitochondrial matrix proteins generating new insights into inner mitochondrial transmembrane protein topology (Rhee et al. 2013; Lam et al. 2015). Importantly, APEX labeling can also be used for electron microscopy experiments allowing a combinatorial approach based on imaging and mass spectrometry to study the spatial distribution of proteins.

With specific reference to mitophagy, an unbiased mass spectrometry-based proteomic screen has supported the idea of intra-mitochondrial protein segregation prior mitophagic degradation. Mitochondrial matrix proteins have been identified with widely diverging rates of mitophagy (Abeliovich et al. 2013). Strikingly, mitochondrial matrix proteins that are inefficiently degraded by mitophagy clearly segregate within the matrix from those undergoing efficient mitophagy, whereas inefficiently degraded proteins appear to concentrate in specific foci inside the mitochondrial matrix, those proteins undergoing efficient mitophagy appear to be evenly distributed (Abeliovich et al. 2013). One interpretation of these results is indeed that a distillation-type process is coupled to mitochondrial dynamics as well as to mitophagic engulfment (Dengjel and Abeliovich 2014).

Proteomic studies using mice also provide indirect support of the concept of intra-mitochondrial selectivity during mitophagy (Kim et al. 2012). Thus, the half-lives of proteins from heart and skeletal muscle mitochondria appear to vary from hours to months, a discrepancy that is irreconcilable with non-selective mitophagy.

\section{Concluding remarks}

Our mechanistic understanding of mitophagy has been boosted by recent studies in mammalian cells. On the other hand, the discovery of stationary phase mitophagy in respiring yeast cells allowed high-throughput genomic screens and supported the identification of critical factors required for this process. Studies in both systems suggest that distinct signaling mechanisms identify mitochondria that are destined for degradation by mitophagy. These signaling mechanisms, however, must also be coupled to intra-mitochondrial mechanisms sorting defective, perhaps oxidized, factors. It appears plausible that these signals activate and use the mitochondrial fusion and fission machinery to "distill" faulty components out of the general mitochondrial milieu. Thus, one can postulate not one, but at least two signaling events: The original overall physiological burden of accumulated and unsorted mitochondrial damage may induce a "sorting" process, while the segregation of defective mitochondrial compartments could induce a specific "eat me" signal mediated by phospho-ubiquitin in mammals and by Atg 32 modifications in yeast. Different classes of genes, which fulfill different tasks during the various stages described, would be predicted to contribute to the overall process. Taken together, much more work, both scientific and intellectual, is needed to test these hypotheses and to identify the underlying molecular machinery, in the mitochondrial compartments as well as in the cytosol and on the membranes of the vesicular compartment.

Acknowledgments Work in the authors' laboratories is funded by Israel Science Foundation grant 422/12, the German-Israel Research Foundation (GIF) grant 1297 and the Swiss National Science Foundation, grant 31003A-166482/1. Both authors are supported by the Freiburg Institute for Advanced Studies.

\section{References}

Abeliovich H (2011) Stationary-phase mitophagy in respiring Saccharomyces cerevisiae. Antioxid Redox Signal 14:2003-2011

Abeliovich H, Dunn WA, Kim J, Klionsky DJ (2000) Dissection of autophagosome biogenesis into distinct nucleation and expansion steps. J Cell Biol 151:1025-1034 
Abeliovich H, Zarei M, Rigbolt KT, Youle RJ, Dengjel J (2013) Involvement of mitochondrial dynamics in the segregation of mitochondrial matrix proteins during stationary phase mitophagy. Nat Commun 4:2789

Abeliovich H, Zhang C, Dunn WA, Shokat KM, Klionsky DJ (2003) Chemical genetic analysis of Apg1 reveals a non-kinase role in the induction of autophagy. Mol Biol Cell 14:477-490

Ahlqvist KJ, Leoncini S, Pecorelli A, Wortmann SB, Ahola S, Forsström S, Guerranti R, De Felice C, Smeitink J, Ciccoli L, Hämäläinen RH, Suomalainen A (2015) MtDNA mutagenesis impairs elimination of mitochondria during erythroid maturation leading to enhanced erythrocyte destruction. Nat Commun 6:6494

Alers S, Löffler AS, Paasch F, Dieterle AM, Keppeler H, Lauber K, Campbell DG, Fehrenbacher B, Schaller M, Wesselborg S, Stork B (2011) Atg13 and FIP200 act independently of Ulk1 and Ulk2 in autophagy induction. Autophagy 7:1423-1433

Aoki Y, Kanki T, Hirota Y, Kurihara Y, Saigusa T, Uchiumi T, Kang D (2011) Phosphorylation of Ser114 on Atg32 mediates mitophagy. Mol Biol Cell 22:3206-3217

Axe EL, Walker SA, Manifava M, Chandra P, Roderick HL, Habermann A, Griffiths G, Ktistakis NT (2008) Autophagosome formation from membrane compartments enriched in phosphatidylinositol 3phosphate and dynamically connected to the endoplasmic reticulum. J Cell Biol 182:685-701

Balaban RS, Nemoto S, Finkel T (2005) Mitochondria, oxidants, and aging. Cell 120:483-495

Behrends C, Sowa ME, Gygi SP, Harper JW (2010) Network organization of the human autophagy system. Nature 466:68-76

Bellot G, Garcia-Medina R, Gounon P, Chiche J, Roux D, Pouysségur J, Mazure NM (2009) Hypoxia-induced autophagy is mediated through hypoxia-inducible factor induction of BNIP3 and BNIP3L via their BH3 domains. Mol Cell Biol 29:2570-2581

Böckler S, Westermann B (2014) Mitochondrial ER contacts are crucial for mitophagy in yeast. Dev Cell 28:450-458

Budovskaya YV, Stephan JS, Reggiori F, Klionsky DJ, Herman PK (2004) The Ras/cAMP-dependent protein kinase signaling pathway regulates an early step of the autophagy process in Saccharomyces cerevisiae. J Biol Chem 279:20663-20671

Busch KB, Kowald A, Spelbrink JN (2014) Quality matters: how does mitochondrial network dynamics and quality control impact on mtDNA integrity. Philos Trans R Soc Lond B 369:20130442

Chan EY, Longatti A, McKnight NC, Tooze SA (2009) Kinaseinactivated ULK proteins inhibit autophagy via their conserved Cterminal domains using an Atg13-independent mechanism. Mol Cell Biol 29:157-171

Chauhan S, Mandell MA, Deretic V (2015) IRGM governs the core autophagy machinery to conduct antimicrobial defense. Mol Cell 58:507-521

Chen Y, Dorn GW (2013) PINK1-phosphorylated mitofusin 2 is a Parkin receptor for culling damaged mitochondria. Science 340:471-475

Cheong H, Lindsten T, Wu J, Lu C, Thompson CB (2011) Ammoniainduced autophagy is independent of ULK1/ULK2 kinases. Proc Natl Acad Sci U S A 108:11121-11126

Cuervo AM (2008) Autophagy and aging: keeping that old broom working. Trends Genet 24:604-612

Cui J, Bai XY, Shi S, Cui S, Hong Q, Cai G, Chen X (2012) Age-related changes in the function of autophagy in rat kidneys. Age (Dordr) 34 : 329-339

Deffieu M, Bhatia-Kissova I, Salin B, Galinier A, Manon S, Camougrand $\mathrm{N}$ (2009) Glutathione participates in the regulation of mitophagy in yeast. J Biol Chem 284:14828-14837

Dengjel J, Abeliovich H (2014) Musical chairs during mitophagy. Autophagy 10:706-707

Deter RL, Baudhuin P, De Duve C (1967) Participation of lysosomes in cellular autophagy induced in rat liver by glucagon. J Cell Biol 35: $\mathrm{C} 11-\mathrm{C} 16$
Diot A, Hinks-Roberts A, Lodge T, Liao C, Dombi E, Morten K, Brady S, Fratter C, Carver J, Muir R, Davis R, Green CJ, Johnston I, HiltonJones D, Sue C, Mortiboys H, Poulton J (2015) A novel quantitative assay of mitophagy: Combining high content fluorescence microscopy and mitochondrial DNA load to quantify mitophagy and identify novel pharmacological tools against pathogenic heteroplasmic mtDNA. Pharmacol Res 100:24-35

Egan DF, Shackelford DB, Mihaylova MM, Gelino S, Kohnz RA, Mair W, Vasquez DS, Joshi A, Gwinn DM, Taylor R, Asara JM, Fitzpatrick J, Dillin A, Viollet B, Kundu M, Hansen M, Shaw RJ (2011) Phosphorylation of ULK1 (hATG1) by AMP-activated protein kinase connects energy sensing to mitophagy. Science 331:456461

Feng Y, He D, Yao Z, Klionsky DJ (2014) The machinery of macroautophagy. Cell Res 24:24-41

Foster LJ, de Hoog CL, Zhang Y, Zhang Y, Xie X, Mootha VK, Mann M (2006) A mammalian organelle map by protein correlation profiling. Cell 125:187-199

Friedman JR, Lackner LL, West M, DiBenedetto JR, Nunnari J, Voeltz GK. (2011) ER tubules mark sites of mitochondrial division. Science 334:358-362

Gong G, Song M, Csordas G, Kelly DP, Matkovich SJ, Dorn GW (2015) Parkin-mediated mitophagy directs perinatal cardiac metabolic maturation in mice. Science 350:aad2459

Gordon PB, Seglen PO (1988) Prelysosomal convergence of autophagic and endocytic pathways. Biochem Biophys Res Commun 151:4047

Goto Y, Nonaka I, Horai S (1990) A mutation in the tRNA(Leu)(UUR) gene associated with the MELAS subgroup of mitochondrial encephalomyopathies. Nature 348:651-653

Greenamyre JT, MacKenzie G, Peng TI, Stephans SE (1999) Mitochondrial dysfunction in Parkinson's disease. Biochem Soc Symp 66:85-97

Hämäläinen RH, Manninen T, Koivumäki H, Kislin M, Otonkoski T, Suomalainen A (2013) Tissue- and cell-type-specific manifestations of heteroplasmic mtDNA 3243A $>$ G mutation in human induced pluripotent stem cell-derived disease model. Proc Natl Acad Sci U S A 110:E3622-E3630

Hanada T, Noda NN, Satomi Y, Ichimura Y, Fujioka Y, Takao T, Inagaki F, Ohsumi Y (2007) The Atg12-Atg5 conjugate has a novel E3-like activity for protein lipidation in autophagy. J Biol Chem 282:3729837302

Hara T, Takamura A, Kishi C, Iemura S, Natsume T, Guan JL, Mizushima N (2008) FIP200, a ULK-interacting protein, is required for autophagosome formation in mammalian cells. J Cell Biol 181: 497-510

Harding TM, Morano KA, Scott SV, Klionsky DJ (1995) Isolation and characterization of yeast mutants in the cytoplasm to vacuole protein targeting pathway. J Cell Biol 131:591-602

Harman D (1956) Aging: a theory based on free radical and radiation chemistry. J Gerontol 11:298-300

Heo JM, Ordureau A, Paulo JA, Rinehart J, Harper JW (2015) The PINK1-PARKIN Mitochondrial Ubiquitylation Pathway Drives a Program of OPTN/NDP52 Recruitment and TBK1 Activation to Promote Mitophagy. Mol Cell 60:7-20

Hosokawa N, Hara T, Kaizuka T, Kishi C, Takamura A, Miura Y, Iemura S, Natsume T, Takehana K, Yamada N, Guan JL, Oshiro N, Mizushima N (2009a) Nutrient-dependent mTORC1 association with the ULK1-Atg13-FIP200 complex required for autophagy. Mol Biol Cell 20:1981-1991

Hosokawa N, Sasaki T, Iemura S, Natsume T, Hara T, Mizushima N (2009b) Atg101, a novel mammalian autophagy protein interacting with Atg13. Autophagy 5:973-979

Hung YH, Chen LM, Yang JY, Yang WY (2013) Spatiotemporally controlled induction of autophagy-mediated lysosome turnover. Nat Commun 4:2111 
Ichimura Y, Kirisako T, Takao T, Satomi Y, Shimonishi Y, Ishihara N, Mizushima N, Tanida I, Kominami E, Ohsumi M, Noda T, Ohsumi Y (2000) A ubiquitin-like system mediates protein lipidation. Nature 408:488-492

Jin SM, Lazarou M, Wang C, Kane LA, Narendra DP, Youle RJ (2010) Mitochondrial membrane potential regulates PINK1 import and proteolytic destabilization by PARL. J Cell Biol 191:933-942

Journo D, Mor A, Abeliovich H (2009) Aup1-mediated regulation of Rtg3 during mitophagy. J Biol Chem 284:35885-35895

Kabeya Y, Kamada Y, Baba M, Takikawa H, Sasaki M, Ohsumi Y (2005) Atg17 functions in cooperation with Atg1 and Atg13 in yeast autophagy. Mol Biol Cell 16:2544-2553

Kamada Y, Funakoshi T, Shintani T, Nagano K, Ohsumi M, Ohsumi Y (2000) Tor-mediated induction of autophagy via an Apg1 protein kinase complex. J Cell Biol 150:1507-1513

Kamber RA, Shoemaker CJ, Denic V (2015) Receptor-Bound Targets of Selective Autophagy Use a Scaffold Protein to Activate the Atg1 Kinase. Mol Cell 59:372-381

Kane LA, Lazarou M, Fogel AI, Li Y, Yamano K, Sarraf SA, Banerjee S, Youle RJ (2014) PINK1 phosphorylates ubiquitin to activate Parkin E3 ubiquitin ligase activity. J Cell Biol 205:143-153

Kanki T, Wang K, Cao Y, Baba M, Klionsky DJ (2009) Atg32 is a mitochondrial protein that confers selectivity during mitophagy. Dev Cell 17:98-109

Kanki T, Wang K, Klionsky DJ (2010) A genomic screen for yeast mutants defective in mitophagy. Autophagy 6:278-280

Kazlauskaite A, Kondapalli C, Gourlay R, Campbell DG, Ritorto MS, Hofmann K, Alessi DR, Knebel A, Trost M, Muqit MM (2014) Parkin is activated by PINK1-dependent phosphorylation of ubiquitin at Ser65. Biochem J 460:127-139

Khaminets A, Heinrich T, Mari M, Grumati P, Huebner AK, Akutsu M, Liebmann L, Stolz A, Nietzsche S, Koch N, Mauthe M, Katona I, Qualmann B, Weis J, Reggiori F, Kurth I, Hübner CA, Dikic I (2015) Regulation of endoplasmic reticulum turnover by selective autophagy. Nature 522:354-358

Kim TY, Wang D, Kim AK, Lau E, Lin AJ, Liem DA, Zhang J, Zong NC, Lam MP, Ping P (2012) Metabolic labeling reveals proteome dynamics of mouse mitochondria. Mol Cell Proteomics 11:1586-1594

Kirisako T, Baba M, Ishihara N, Miyazawa K, Ohsumi M, Yoshimori T, Noda T, Ohsumi Y (1999) Formation process of autophagosome is traced with Apg8/Aut7p in yeast. J Cell Biol 147:435-446

Kissova I, Deffieu M, Manon S, Camougrand N (2004) Uthlp is involved in the autophagic degradation of mitochondria. J Biol Chem 279: 39068-39074

Klionsky DJ, Cueva R, Yaver DS (1992) Aminopeptidase I of Saccharomyces cerevisiae is localized to the vacuole independent of the secretory pathway. J Cell Biol 119:287-299

Köfinger J, Ragusa MJ, Lee IH, Hummer G, Hurley JH (2015) Solution structure of the Atg1 complex: implications for the architecture of the phagophore assembly site. Structure 23:809-818

Kondapalli C, Kazlauskaite A, Zhang N, Woodroof HI, Campbell DG, Gourlay R, Burchell L, Walden H, Macartney TJ, Deak M, Knebel A, Alessi DR, Muqit MM (2012) PINK1 is activated by mitochondrial membrane potential depolarization and stimulates Parkin E3 ligase activity by phosphorylating Serine 65. Open Biol 2:120080

Koopmann R, Muhammad K, Perbandt M, Betzel C, Duszenko M (2009) Trypanosoma brucei ATG8: structural insights into autophagic-like mechanisms in protozoa. Autophagy 5:1085-1091

Koyano F, Okatsu K, Kosako H, Tamura Y, Go E, Kimura M, Kimura Y, Tsuchiya H, Yoshihara H, Hirokawa T, Endo T, Fon EA, Trempe JF, Saeki Y, Tanaka K, Matsuda N (2014) Ubiquitin is phosphorylated by PINK1 to activate parkin. Nature 510:162-166

Kraft C, Peter M (2008) Is the Rsp5 ubiquitin ligase involved in the regulation of ribophagy. Autophagy 4:838-840

Ktistakis NT, Tooze SA (2016) Digesting the expanding mechanisms of autophagy. Trends Cell Biol (in press)
Kuma A, Mizushima N, Ishihara N, Ohsumi Y (2002) Formation of the approximately 350-kDa Apg12-Apg5.Apg16 multimeric complex, mediated by Apg 16 oligomerization, is essential for autophagy in yeast. J Biol Chem 277:18619-18625

Kumaran R, Cookson MR (2015) Pathways to Parkinsonism Redux: convergent pathobiological mechanisms in genetics of Parkinson's disease. Hum Mol Genet 24:R32-44

Lam SS, Martell JD, Kamer KJ, Deerinck TJ, Ellisman MH, Mootha VK, Ting AY (2015) Directed evolution of APEX2 for electron microscopy and proximity labeling. Nat Methods 12:51-54

Lazarou M, Sliter DA, Kane LA, Sarraf SA, Wang C, Burman JL, Sideris DP, Fogel AI, Youle RJ (2015) The ubiquitin kinase PINK1 recruits autophagy receptors to induce mitophagy. Nature 524:309-314

Lin MG, Hurley JH (2016) Structure and function of the ULK1 complex in autophagy. Curr Opin Cell Biol 39:61-68

Lipinski MM, Zheng B, Lu T, Yan Z, Py BF, Ng A, Xavier RJ, Li C, Yankner BA, Scherzer CR, Yuan J (2010) Genome-wide analysis reveals mechanisms modulating autophagy in normal brain aging and in Alzheimer's disease. Proc Natl Acad Sci U S A 107:14164 14169

Liu L, Feng D, Chen G, Chen M, Zheng Q, Song P, Ma Q, Zhu C, Wang R, Qi W, Huang L, Xue P, Li B, Wang X, Jin H, Wang J, Yang F, Liu P, Zhu Y, Sui S, Chen Q (2012) Mitochondrial outer-membrane protein FUNDC1 mediates hypoxia-induced mitophagy in mammalian cells. Nat Cell Biol 14:177-185

Mancias JD, Wang X, Gygi SP, Harper JW, Kimmelman AC (2014) Quantitative proteomics identifies NCOA4 as the cargo receptor mediating ferritinophagy. Nature 509:105-109

Mao K, Wang K, Liu X, Klionsky DJ (2013) The scaffold protein Atg11 recruits fission machinery to drive selective mitochondria degradation by autophagy. Dev Cell 26:9-18

Mari M, Griffith J, Rieter E, Krishnappa L, Klionsky DJ, Reggiori F (2010) An Atg9-containing compartment that functions in the early steps of autophagosome biogenesis. J Cell Biol 190:1005-1022

Matsuda N, Sato S, Shiba K, Okatsu K, Saisho K, Gautier CA, Sou YS, Saiki S, Kawajiri S, Sato F, Kimura M, Komatsu M, Hattori N, Tanaka K (2010) PINK1 stabilized by mitochondrial depolarization recruits Parkin to damaged mitochondria and activates latent Parkin for mitophagy. J Cell Biol 189:211-221

Matsuura A, Tsukada M, Wada Y, Ohsumi Y (1997) Apglp, a novel protein kinase required for the autophagic process in Saccharomyces cerevisiae. Gene 192:245-250

Meissner C, Lorenz H, Weihofen A, Selkoe DJ, Lemberg MK (2011) The mitochondrial intramembrane protease PARL cleaves human Pink1 to regulate Pink1 trafficking. J Neurochem 117:856-867

Mercer CA, Kaliappan A, Dennis PB (2009) A novel, human Atg13 binding protein, Atg101, interacts with ULK1 and is essential for macroautophagy. Autophagy 5:649-662

Mijaljica D, Devenish RJ (2013) Nucleophagy at a glance. J Cell Sci 126: 4325-4330

Mizushima N, Noda T, Yoshimori T, Tanaka Y, Ishii T, George MD, Klionsky DJ, Ohsumi M, Ohsumi Y (1998) A protein conjugation system essential for autophagy. Nature 395:395-398

Mochida K, Oikawa Y, Kimura Y, Kirisako H, Hirano H, Ohsumi Y, Nakatogawa H (2015) Receptor-mediated selective autophagy degrades the endoplasmic reticulum and the nucleus. Nature 522:359362

Mootha VK, Bunkenborg J, Olsen JV, Hjerrild M, Wisniewski JR, Stahl E, Bolouri MS, Ray HN, Sihag S, Kamal M, Patterson N, Lander ES, Mann M (2003) Integrated analysis of protein composition, tissue diversity, and gene regulation in mouse mitochondria. Cell 115:629-640

Nakatogawa H, Ichimura Y, Ohsumi Y (2007) Atg8, a ubiquitin-like protein required for autophagosome formation, mediates membrane tethering and hemifusion. Cell 130:165-178 
Narendra D, Tanaka A, Suen DF, Youle RJ (2008) Parkin is recruited selectively to impaired mitochondria and promotes their autophagy. J Cell Biol 183:795-803

Narendra DP, Jin SM, Tanaka A, Suen DF, Gautier CA, Shen J, Cookson MR, Youle RJ (2010) PINK1 is selectively stabilized on impaired mitochondria to activate Parkin. PLoS Biol 8, e1000298

Noda NN, Satoo K, Fujioka Y, Kumeta H, Ogura K, Nakatogawa H, Ohsumi Y, Inagaki F (2011) Structural basis of Atg8 activation by a homodimeric E1, Atg7. Mol Cell 44:462-475

Noda T, Matsuura A, Wada Y, Ohsumi Y (1995) Novel system for monitoring autophagy in the yeast Saccharomyces cerevisiae. Biochem Biophys Res Commun 210:126-132

Novak I, Kirkin V, McEwan DG, Zhang J, Wild P, Rozenknop A, Rogov V, Löhr F, Popovic D, Occhipinti A, Reichert AS, Terzic J, Dötsch V, Ney PA, Dikic I (2010) Nix is a selective autophagy receptor for mitochondrial clearance. EMBO Rep 11:45-51

Nowikovsky K, Reipert S, Devenish RJ, Schweyen RJ (2007) Mdm38 protein depletion causes loss of mitochondrial $\mathrm{K}+\mathrm{H}+$ exchange activity, osmotic swelling and mitophagy. Cell Death Differ 14: $1647-1656$

Ordureau A, Sarraf SA, Duda DM, Heo JM, Jedrychowski MP, Sviderskiy VO, Olszewski JL, Koerber JT, Xie T, Beausoleil SA, Wells JA, Gygi SP, Schulman BA, Harper JW (2014) Quantitative proteomics reveal a feedforward mechanism for mitochondrial PARKIN translocation and ubiquitin chain synthesis. Mol Cell 56: 360-375

Okamoto K, Kondo-Okamoto N, Ohsumi Y (2009) Mitochondriaanchored receptor Atg32 mediates degradation of mitochondria via selective autophagy. Dev Cell 17:87-97

Ong SE, Blagoev B, Kratchmarova I, Kristensen DB, Steen H, Pandey A, Mann M (2002) Stable isotope labeling by amino acids in cell culture, SILAC, as a simple and accurate approach to expression proteomics. Mol Cell Proteomics 1:376-386

Orsi A, Razi M, Dooley HC, Robinson D, Weston AE, Collinson LM, Tooze SA (2012) Dynamic and transient interactions of Atg9 with autophagosomes, but not membrane integration, are required for autophagy. Mol Biol Cell 23:1860-1873

Øverbye A, Fengsrud M, Seglen PO (2007) Proteomic analysis of membrane-associated proteins from rat liver autophagosomes. Autophagy 3:300-322

Pagliarini DJ, Calvo SE, Chang B, Sheth SA, Vafai SB, Ong SE, Walford GA, Sugiana C, Boneh A, Chen WK, Hill DE, Vidal M, Evans JG, Thorburn DR, Carr SA, Mootha VK (2008) A mitochondrial protein compendium elucidates complex I disease biology. Cell 134:112123

Papinski D, Kraft C (2014) Atg1 kinase organizes autophagosome formation by phosphorylating Atg9. Autophagy 10:1338-1340

Papinski D, Schuschnig M, Reiter W, Wilhelm L, Barnes CA, Maiolica A, Hansmann I, Pfaffenwimmer T, Kijanska M, Stoffel I, Lee SS, Brezovich A, Lou JH, Turk BE, Aebersold R, Ammerer G, Peter M, Kraft C (2014) Early steps in autophagy depend on direct phosphorylation of Atg9 by the Atg1 kinase. Mol Cell 53:471-483

Paz Y, Elazar Z, Fass D (2000) Structure of GATE-16, membrane transport modulator and mammalian ortholog of autophagocytosis factor Aut7p. J Biol Chem 275:25445-25450

Petrungaro C, Zimmermann KM, Küttner V, Fischer M, Dengjel J, Bogeski I, Riemer J (2015) The $\mathrm{Ca}(2+)$-Dependent Release of the Mia40-Induced MICU1-MICU2 Dimer from MCU Regulates Mitochondrial Ca(2+) Uptake. Cell Metab 22:721-733

Pickrell AM, Huang CH, Kennedy SR, Ordureau A, Sideris DP, Hoekstra JG, Harper JW, Youle RJ (2015) Endogenous Parkin Preserves Dopaminergic Substantia Nigral Neurons following Mitochondrial DNA Mutagenic Stress. Neuron 87:371-381

Pickrell AM, Youle RJ (2013) Mitochondrial disease: mtDNA and protein segregation mysteries in iPSCs. Curr Biol 23:R1052-R1054
Polson HE, de Lartigue J, Rigden DJ, Reedijk M, Urbé S, Clague MJ, Tooze SA (2010) Mammalian Atg18 (WIPI2) localizes to omegasome-anchored phagophores and positively regulates LC3 lipidation. Autophagy 6:506-522

Priault M, Salin B, Schaeffer J, Vallette FM, di Rago JP, Martinou JC (2005) Impairing the bioenergetic status and the biogenesis of mitochondria triggers mitophagy in yeast. Cell Death Differ 12:16131621

Proikas-Cezanne T, Waddell S, Gaugel A, Frickey T, Lupas A, Nordheim A (2004) WIPI-1alpha (WIPI49), a member of the novel 7-bladed WIPI protein family, is aberrantly expressed in human cancer and is linked to starvation-induced autophagy. Oncogene 23:9314-9325

Radoshevich L, Murrow L, Chen N, Fernandez E, Roy S, Fung C, Debnath J (2010) ATG12 conjugation to ATG3 regulates mitochondrial homeostasis and cell death. Cell 142:590-600

Ragusa MJ, Stanley RE, Hurley JH (2012) Architecture of the Atg17 complex as a scaffold for autophagosome biogenesis. Cell 151: 1501-1512

Rao Y, Perna MG, Hofmann B, Beier V, Wollert T (2016) The Atg1kinase complex tethers Atg9-vesicles to initiate autophagy. Nat Commun 7:10338

Rees JS, Li XW, Perrett S, Lilley KS, Jackson AP (2015) Protein Neighbors and Proximity Proteomics. Mol Cell Proteomics 14: 2848-2856

Reinders J, Wagner K, Zahedi RP, Stojanovski D, Eyrich B, van der Laan M, Rehling P, Sickmann A, Pfanner N, Meisinger C (2007) Profiling phosphoproteins of yeast mitochondria reveals a role of phosphorylation in assembly of the ATP synthase. Mol Cell Proteomics 6: 1896-1906

Rhee HW, Zou P, Udeshi ND, Martell JD, Mootha VK, Carr SA, Ting AY (2013) Proteomic mapping of mitochondria in living cells via spatially restricted enzymatic tagging. Science 339:1328-1331

Richter B, Sliter DA, Herhaus L, Stolz A, Wang C, Beli P, Zaffagnini G, Wild P, Martens S, Wagner SA, Youle RJ, Dikic I (2016) Phosphorylation of OPTN by TBK1 enhances its binding to Ub chains and promotes selective autophagy of damaged mitochondria. Proc Natl Acad Sci U S A. doi:10.1073/pnas. 1523926113

Rodriguez-Enriquez S, He L, Lemasters JJ (2004) Role of mitochondrial permeability transition pores in mitochondrial autophagy. Int $\mathrm{J}$ Biochem Cell Biol 36:2463-2472

Rodriguez-Enriquez S, Kai Y, Maldonado E, Currin RT, Lemasters JJ (2009) Roles of mitophagy and the mitochondrial permeability transition in remodeling of cultured rat hepatocytes. Autophagy 5:10991106

Rodriguez-Enriquez S, Kim I, Currin RT, Lemasters JJ (2006) Tracker dyes to probe mitochondrial autophagy (mitophagy) in rat hepatocytes. Autophagy 2:39-46

Saitoh T, Fujita N, Hayashi T, Takahara K, Satoh T, Lee H, Matsunaga K, Kageyama S, Omori H, Noda T, Yamamoto N, Kawai T, Ishii K, Takeuchi O, Yoshimori T, Akira S (2009) Atg9a controls dsDNAdriven dynamic translocation of STING and the innate immune response. Proc Natl Acad Sci U S A 106:20842-20846

Sakakibara K, Eiyama A, Suzuki SW, Sakoh-Nakatogawa M, Okumura N, Tani M, Hashimoto A, Nagumo S, Kondo-Okamoto N, KondoKakuta C, Asai E, Kirisako H, Nakatogawa H, Kuge O, Takao T, Ohsumi Y, Okamoto K (2015) Phospholipid methylation controls Atg32-mediated mitophagy and Atg8 recycling. EMBO J 34:27032719

Saksena S, Sun J, Chu T, Emr SD (2007) ESCRTing proteins in the endocytic pathway. Trends Biochem Sci 32:561-573

Sanchez-Wandelmer J, Reggiori F (2013) Amphisomes: out of the autophagosome shadow. EMBO J 32:3116-3118

Sandoval H, Thiagarajan P, Dasgupta SK, Schumacher A, Prchal JT, Chen M, Wang J (2008) Essential role for Nix in autophagic maturation of erythroid cells. Nature 454:232-235 
Scherz-Shouval R, Shvets E, Fass E, Shorer H, Gil L, Elazar Z (2007) Reactive oxygen species are essential for autophagy and specifically regulate the activity of Atg4. EMBO J 26:1749-1760

Schneider JL, Cuervo AM (2014) Autophagy and human disease: emerging themes. Curr Opin Genet Dev 26:16-23

Scott CC, Vacca F, Gruenberg J (2014) Endosome maturation, transport and functions. Semin Cell Dev Biol 31:2-10

Shiba-Fukushima K, Imai Y, Yoshida S, Ishihama Y, Kanao T, Sato S, Hattori N (2012) PINK1-mediated phosphorylation of the Parkin ubiquitin-like domain primes mitochondrial translocation of Parkin and regulates mitophagy. Sci Rep 2:1002

Shintani T, Huang WP, Stromhaug PE, Klionsky DJ (2002) Mechanism of cargo selection in the cytoplasm to vacuole targeting pathway. Dev Cell 3:825-837

Shpilka T, Weidberg H, Pietrokovski S, Elazar Z (2011) Atg8: an autophagy-related ubiquitin-like protein family. Genome Biol 12: 226

Sickmann A, Reinders J, Wagner Y, Joppich C, Zahedi R, Meyer HE, Schönfisch B, Perschil I, Chacinska A, Guiard B, Rehling P, Pfanner N, Meisinger C (2003) The proteome of Saccharomyces cerevisiae mitochondria. Proc Natl Acad Sci U S A 100:13207-13212

Simonsen A, Wurmser AE, Emr SD, Stenmark H (2001) The role of phosphoinositides in membrane transport. Curr Opin Cell Biol 13: 485-492

Sin J, Andres AM, Taylor DJ, Weston T, Hiraumi Y, Stotland A, Kim BJ, Huang C, Doran KS, Gottlieb RA (2016) Mitophagy is required for mitochondrial biogenesis and myogenic differentiation of $\mathrm{C} 2 \mathrm{C} 12$ myoblasts. Autophagy 12:369-380

Singh SB, Davis AS, Taylor GA, Deretic V (2006) Human IRGM induces autophagy to eliminate intracellular mycobacteria. Science 313:1438-1441

Singh R, Kaushik S, Wang Y, Xiang Y, Novak I, Komatsu M, Tanaka K, Cuervo AM, Czaja MJ (2009) Autophagy regulates lipid metabolism. Nature 458:1131-1135

Soulard A, Cremonesi A, Moes S, Schütz F, Jenö P, Hall MN (2010) The rapamycin-sensitive phosphoproteome reveals that TOR controls protein kinase A toward some but not all substrates. Mol Biol Cell 21:3475-3486

Stack JH, Horazdovsky B, Emr SD (1995) Receptor-mediated protein sorting to the vacuole in yeast: roles for a protein kinase, a lipid kinase and GTP-binding proteins. Annu Rev Cell Dev Biol 11:1-33

Stolz A, Ernst A, Dikic I (2014) Cargo recognition and trafficking in selective autophagy. Nat Cell Biol 16:495-501

Suen DF, Narendra DP, Tanaka A, Manfredi G, Youle RJ (2010) Parkin overexpression selects against a deleterious mtDNA mutation in heteroplasmic cybrid cells. Proc Natl Acad Sci U S A 107:1183511840

Sugawara K, Suzuki NN, Fujioka Y, Mizushima N, Ohsumi Y, Inagaki F (2004) The crystal structure of microtubule-associated protein light chain 3, a mammalian homologue of Saccharomyces cerevisiae Atg8. Genes Cells 9:611-618

Suzuki SW, Yamamoto H, Oikawa Y, Kondo-Kakuta C, Kimura Y, Hirano H, Ohsumi Y (2015) Atg13 HORMA domain recruits Atg9 vesicles during autophagosome formation. Proc Natl Acad Sci U S A 112:3350-3355

Tabata K, Matsunaga K, Sakane A, Sasaki T, Noda T, Yoshimori T (2010) Rubicon and PLEKHM1 negatively regulate the endocytic/ autophagic pathway via a novel Rab7-binding domain. Mol Biol Cell 21:4162-4172

Takeshige K, Baba M, Tsuboi S, Noda T, Ohsumi Y (1992) Autophagy in yeast demonstrated with proteinase-deficient mutants and conditions for its induction. J Cell Biol 119:301-311

Tal R, Winter G, Ecker N, Klionsky DJ, Abeliovich H (2007) Auplp, a yeast mitochondrial protein phosphatase homolog, is required for efficient stationary phase mitophagy and cell survival. J Biol Chem 282:5617-5624
Tanaka A, Cleland MM, Xu S, Narendra DP, Suen DF, Karbowski M, Youle RJ (2010) Proteasome and p97 mediate mitophagy and degradation of mitofusins induced by Parkin. J Cell Biol 191:13671380

Thumm M, Egner R, Koch B, Schlumpberger M, Straub M, Veenhuis M, Wolf DH (1994) Isolation of autophagocytosis mutants of Saccharomyces cerevisiae. FEBS Lett 349:275-280

Thurston TL, Ryzhakov G, Bloor S, von Muhlinen N, Randow F (2009) The TBK1 adaptor and autophagy receptor NDP52 restricts the proliferation of ubiquitin-coated bacteria. Nat Immunol 10:12151221

Tsukada M, Ohsumi Y (1993) Isolation and characterization of autophagy-defective mutants of Saccharomyces cerevisiae. FEBS Lett 333:169-174

Twig G, Elorza A, Molina AJ, Mohamed H, Wikstrom JD, Walzer G, Stiles L, Haigh SE, Katz S, Las G, Alroy J, Wu M, Py BF, Yuan J, Deeney JT, Corkey BE, Shirihai OS (2008) Fission and selective fusion govern mitochondrial segregation and elimination by autophagy. EMBO J 27:433-446

Vittorini S, Paradiso C, Donati A, Cavallini G, Masini M, Gori Z, Pollera M, Bergamini E (1999) The age-related accumulation of protein carbonyl in rat liver correlates with the age-related decline in liver proteolytic activities. J Gerontol A 54:B318-B323

Vögtle FN, Burkhart JM, Rao S, Gerbeth C, Hinrichs J, Martinou JC, Chacinska A, Sickmann A, Zahedi RP, Meisinger C (2012) Intermembrane space proteome of yeast mitochondria. Mol Cell Proteomics 11:1840-1852

Wallace DC (1999) Mitochondrial diseases in man and mouse. Science 283:1482-1488

Wallace DC (2005) A mitochondrial paradigm of metabolic and degenerative diseases, aging, and cancer: a dawn for evolutionary medicine. Annu Rev Genet 39:359-407

Wallace DC (2010) Mitochondrial DNA mutations in disease and aging. Environ Mol Mutagen 51:440-450

Wallace DC, Chalkia D (2013) Mitochondrial DNA genetics and the heteroplasmy conundrum in evolution and disease. Cold Spring Harb Perspect Biol 5:a021220

Wang T, Hay JC (2015) Alpha-synuclein toxicity in the early secretory pathway: how it drives neurodegeneration in Parkinsons Disease. Front Neurosci 9:433

Wang K, Jin M, Liu X, Klionsky DJ (2013) Proteolytic processing of Atg32 by the mitochondrial i-AAA protease Yme1 regulates mitophagy. Autophagy 9:1828-1836

Wild P, Farhan H, McEwan DG, Wagner S, Rogov VV, Brady NR, Richter B, Korac J, Waidmann O, Choudhary C, Dötsch V, Bumann D, Dikic I (2011) Phosphorylation of the autophagy receptor optineurin restricts Salmonella growth. Science 333:228-233

Wilkens V, Kohl W, Busch K (2013) Restricted diffusion of OXPHOS complexes in dynamic mitochondria delays their exchange between cristae and engenders a transitory mosaic distribution. J Cell Sci 126: $103-116$

Wong E, Bejarano E, Rakshit M, Lee K, Hanson HH, Zaarur N, Phillips GR, Sherman MY, Cuervo AM (2012) Molecular determinants of selective clearance of protein inclusions by autophagy. Nat Commun 3:1240

Wrobel L, Topf U, Bragoszewski P, Wiese S, Sztolsztener ME, Oeljeklaus S, Varabyova A, Lirski M, Chroscicki P, Mroczek S, Januszewicz E, Dziembowski A, Koblowska M, Warscheid B, Chacinska A (2015) Mistargeted mitochondrial proteins activate a proteostatic response in the cytosol. Nature 524:485-488

Xie Z, Nair U, Klionsky DJ (2008) Atg8 controls phagophore expansion during autophagosome formation. Mol Biol Cell 19:3290-3298

Yamamoto H, Kakuta S, Watanabe TM, Kitamura A, Sekito T, KondoKakuta C, Ichikawa R, Kinjo M, Ohsumi Y (2012) Atg9 vesicles are an important membrane source during early steps of autophagosome formation. J Cell Biol 198:219-233 
Yamano K, Youle RJ (2013) PINK1 is degraded through the N-end rule pathway. Autophagy 9:1758-1769

Yorimitsu T, Zaman S, Broach JR, Klionsky DJ. (2007) Protein kinase A and Sch9 cooperatively regulate induction of autophagy in Saccharomyces cerevisiae. Mol Biol Cell 18:4180-4189

Young AR, Chan EY, Hu XW, Köchl R, Crawshaw SG, High S, Hailey DW, Lippincott-Schwartz J, Tooze SA (2006) Starvation and ULK1-dependent cycling of mammalian Atg9 between the TGN and endosomes. J Cell Sci 119:3888-3900
Zhang H, Bosch-Marce M, Shimoda LA, Tan YS, Baek JH, Wesley JB, Gonzalez FJ, Semenza GL (2008) Mitochondrial autophagy is an HIF-1-dependent adaptive metabolic response to hypoxia. J Biol Chem 283:10892-10903

Ziviani E, Tao RN, Whitworth AJ (2010) Drosophila parkin requires PINK1 for mitochondrial translocation and ubiquitinates mitofusin. Proc Natl Acad Sci U S A 107:5018-5023

Ziviani E, Whitworth AJ (2010) How could Parkin-mediated ubiquitination of mitofusin promote mitophagy? Autophagy 6:660-662 